Article

\title{
Optimal Design of a Multibrid Permanent Magnet Generator for a Tidal Stream Turbine
}

\author{
Khalil Touimi ${ }^{1,2} \mathbb{D}$, Mohamed Benbouzid ${ }^{1,3, * \mathbb{D}}$ and Zhe Chen 4 \\ 1 Institut de recherche Dupuy de Lôme (UMR CNRS 6017 IRDL), University of Brest, 29238 Brest, France; \\ Khalil.Touimi@univ-brest.fr \\ 2 École Militaire Polytechnique, 16111 Alger, Algeria \\ 3 Logistics Engineering College, Shanghai Maritime University, Shanghai 201306, China \\ 4 Department of Energy Technology, Aalborg University, 9220 Aalborg, Denmark; zch@et.aau.dk \\ * Correspondence: Mohamed.Benbouzid@univ-brest.fr; Tel.: +33-2980-18007
}

Received: 15 November 2019; Accepted: 16 January 2020; Published: 19 January 2020

check for updates

\begin{abstract}
Tidal stream energy is acquiring more attention as a future potential renewable energy source. Considering the harsh submarine environment, the main challenges that face the tidal stream turbine (TST) industry are cost and reliability. Hence, simple and reliable technologies, especially considering the drivetrain, are preferred. The multibrid drivetrain configuration with only a single stage gearbox is one of the promising concepts for TST systems. In this context, this paper proposes the design optimization of a multibrid permanent magnet generator (PMG), the design of a planetary gearbox, and afterwards analyzes the multibrid concept cost-effectiveness for TST applications. Firstly, the system analytical model, which consists of a single-stage gearbox and a medium speed PMG, is presented. The optimization methodology is afterwards highlighted. Lastly, the multibrid system optimization results for different gear ratios including the direct-drive topology are discussed and compared where the suitable gear ratio (topology) is investigated. The achieved results show that the multibrid concept in TST applications seems more attractive than the direct-drive one especially for high power ratings.
\end{abstract}

Keywords: tidal stream turbine; multibrid concept; direct-drive; permanent magnet generator; single stage gearbox; design optimization

\section{Introduction}

Tidal stream energy is one of the promising renewable energy sources, which is highly predictable and its potential can exceed $120 \mathrm{GW}$ [1,2]. It is mainly harnessed by horizontal axis turbines where the marine current kinetic power is converted into an electrical one. Despite the infancy of tidal stream turbine (TST) technologies, various machines and prototypes have been developed in recent decades, and different concepts are competing for supremacy [3-5]. In addition to the technology infancy, the harsh submarine environment increases the criticality of the TST subsystems. Therefore, the main challenges that face the tidal stream turbine industry are the energy cost and the system reliability, which means simple and reliable technologies should be adopted. Drivetrain and generator topology choice typically affects the availability of the system as well as the produced energy cost. The main TST configuration types are gearless TST (direct-drive), mechanically geared TST, and magnetically geared TST [6-8].

Direct-drive topology (Figure 1), which was designed to avoid gearbox failures in wind turbines, is attractive due to its simplicity and its high reliability. However, direct-drive generators are non-standard electric machines and have some disadvantages such as the heavy weight, large diameter, and therefore high cost. Geared generators are compact, robust, and economically available compared 
to direct-drive ones, in addition to the fact that mechanical gearbox technologies are mature. Moreover, authors in [9] addressed the criticality of wind turbine subsystems in different sites and provided a comparison between geared and direct-drive wind turbines. The study shows that direct-drive systems are less reliable than geared ones. However, mechanical gearboxes are still critical subsystems, which can lower tidal stream turbines availability [10]. In [11] a comparative study between direct-drive tidal stream turbines and gearbox driven ones has been carried out, where the result suggested the multibrid concept as an alternative compact drivetrain for TST applications in terms of reliability and availability.

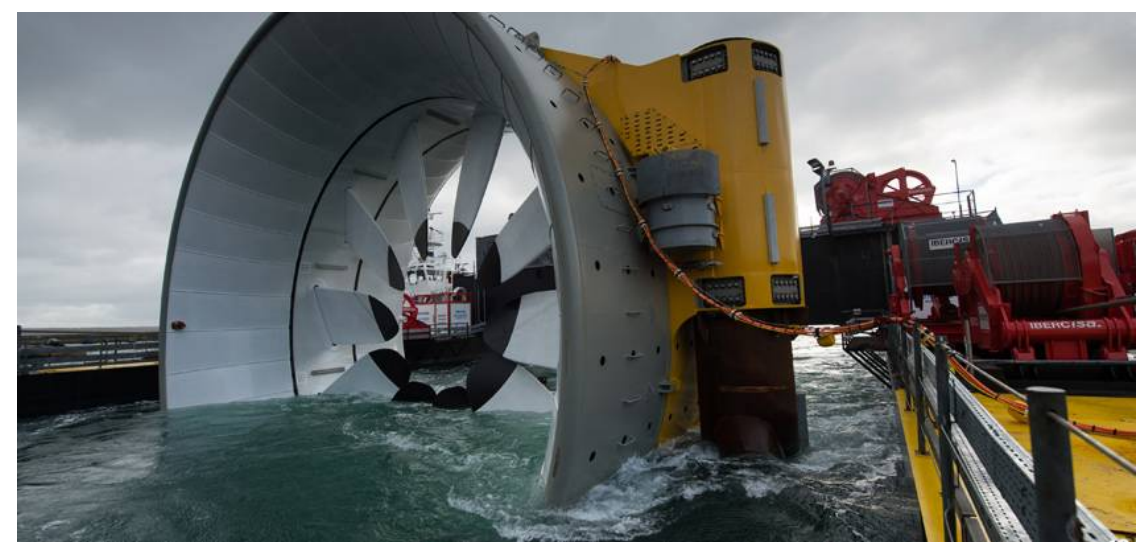

Figure 1. OpenHydro/Naval Energies direct-drive tidal stream turbine [4].

The multibrid configuration (Figure 2a), with a single-stage planetary gearbox associated to a medium speed PMG, combines the advantages of both geared and gearless drivetrain [12]. Indeed, a medium speed generator is cheaper and more efficient than a direct-drive one and a single-stage gearbox is lighter and more reliable than a multiple-stage one. Wind turbines manufacturers have developed multibrid technology such as Multibrid (M5000) and WinWind (WWD-3) [13] (Figure 2b), [14]. The same concept has been designed, realized, and tested for a small scale TST system in the Chinese Zhoushan water channel [15] (Figure 3).

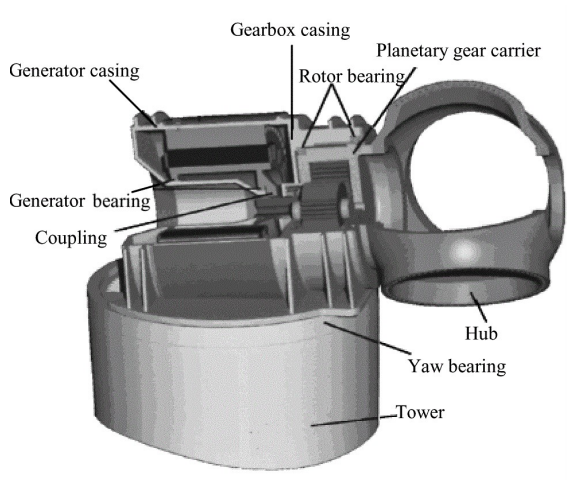

(a)

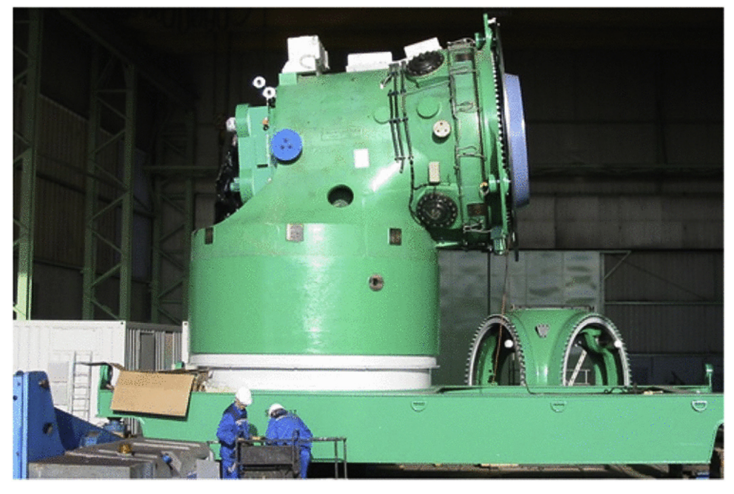

(b)

Figure 2. The multibrid concept: (a) Schematic illustration [12], (b) The AREVA Multibrid M5000 5 MW wind turbine nacelle [11].

The cost of a Multibrid TST depends on the gearbox ratio and the generator diameter. Gearboxes with high gear ratio are heavier and more expensive. However, their high-speed output leads to cheaper generators with low diameter. Hence, to determine the appropriate gearbox ratio and generator dimensions for given specifications, a system optimization is required by minimizing its active parts cost. 


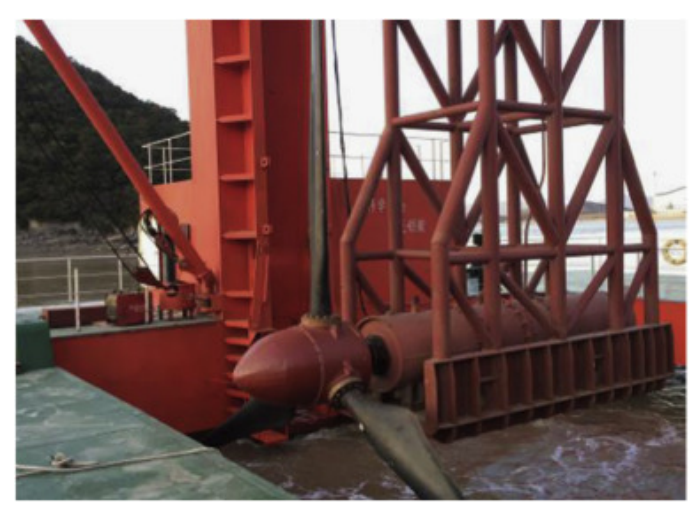

Figure 3. Small scale multibrid tidal stream turbine [15].

Previous studies on wind turbine systems compared geared generators (including single stage gearbox driven ones) to direct-drive generators in terms of cost. In [16], the authors compared quantitatively different drive-train configurations and different generator topologies. In this study, which highlights the multibrid concept, the design of the generators is not optimized and the gear ratio is chosen in advance. In [17] and based on [16], the authors have estimated and compared the cost of energy of different drive-train configurations. Unlike the above-cited papers, Hui et al. [12] have investigated gearbox ratios and power ratings cost-effective ranges of multibrid permanent magnet wind generators including direct-drive ones. Concerning TST design optimization, in $[5,18]$, the authors compared different optimized direct-drive PMG topologies (rim-driven vs. pod assembly and radial flux vs. axial flux PMG). However, for the geared drive-train configuration especially, the multibrid concept was not considered. Even if the wind turbine systems seem similar to TST ones, some fundamental differences on design and operation require more investigation, such as biofouling and marine current turbulence $[19,20]$. Therefore, both the blades and yaw pitch subsystems are avoided due to their high criticality in such a hostile environment [9].

In this paper, a design optimization of PMG for TST system is proposed in order to analyze the cost-effectiveness of the multibrid concept and compare it to the direct-drive one. In this context, the Multibrid TST analytical model is presented and it consists of: the turbine model, the single stage planetary gearbox model, the three-phase PMG two-dimensional (2D) electromagnetic model, and the power electronics converter model. Figure 4 is therefore illustrating a grid-connected single stage gearbox driven PMG, highlighting each subsystem. The proposed design optimization process is performed using the interior-point method to minimize the active material cost of the generator. The suitable drivetrain configuration is afterwards investigated for different power ratings $(500 \mathrm{~kW}$, $1.5 \mathrm{MW}$, and $5 \mathrm{MW}$ ) and the achieved results are compared and discussed.

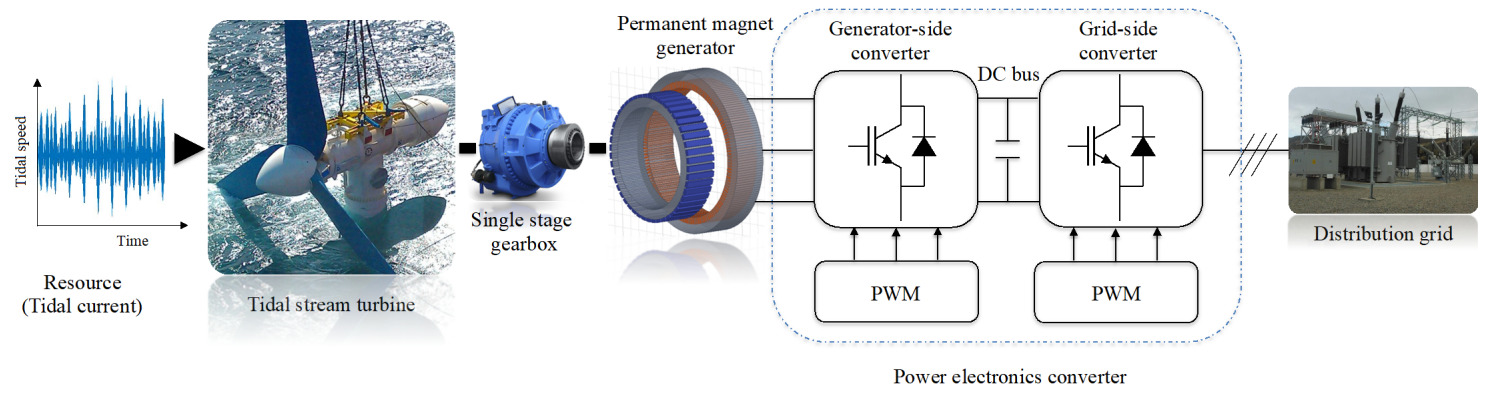

Figure 4. Scheme of a grid-connected single stage permanent magnet generator-based tidal stream turbine. 


\section{System Modeling}

\subsection{Renewable Resource and Tidal Turbine Modeling}

Tidal current velocity data in the site near Ouessant Island were collected by the French navy hydrographic and oceanographic service [21]. The amplitude and direction measurements of the tidal current velocity are done hourly during one year $(8760 \mathrm{~h})$. The optimal direction, which provides the maximum of energy, is calculated as described in [22] (Figure 5). Tidal speed through the optimal direction is shown in Figure 6.

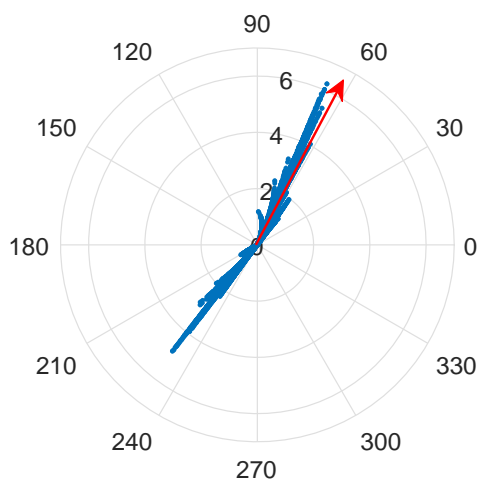

Figure 5. Tidal velocity in polar coordinates.

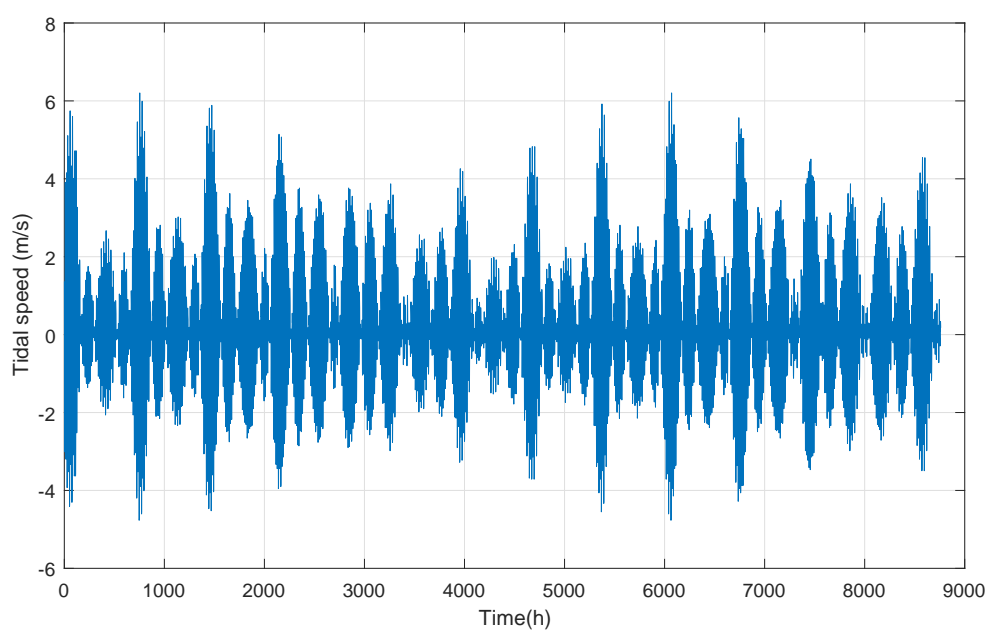

Figure 6. Tidal velocity in the Ouessant Island.

\subsubsection{Power and Energy Calculation}

Energy calculation is done considering the optimal angle direction $\left(61^{\circ}\right)$. Concerning the input shaft power from a tidal turbine, it is calculated as a function of tidal currents speed and the turbine rotor diameter.

$$
P_{T}=\frac{1}{2} \rho C_{p}(\lambda, \beta) A_{t} v^{3},
$$

where $A_{t}=\frac{1}{4} \pi D^{2}$ is the turbine blade swept area, $\rho$ is the sea water density, $C_{p}(\lambda, \beta)$ is the power coefficient which is a function of tip speed ratio $(\lambda)$ and the pitch angle of the tidal turbine blades $(\beta)$.

The annual energy production (AEP) can be calculated by summing the harnessed energy in each hour (the tidal current speed is assumed non-variable). Figure 7 shows the energy distribution according to tidal current speed amplitude in the Ouessant site.

$$
A E P=\int_{v_{i}}^{v_{n}} P_{T}(|v|) O C C(|v|) d v+P_{T r} \int_{v_{n}}^{v_{c}} \operatorname{OCC}(|v|) d v,
$$


where $v_{i}$ is the cut-in tidal current speed, $v_{\mathcal{c}}$ is the cut-out tidal current speed, $v_{n}$ is the rated tidal current speed, and $P_{T r}$ is the rated input shaft power.

The $O C C(|v|)$ function represents the tidal current speed amplitude distribution (Figure 8).

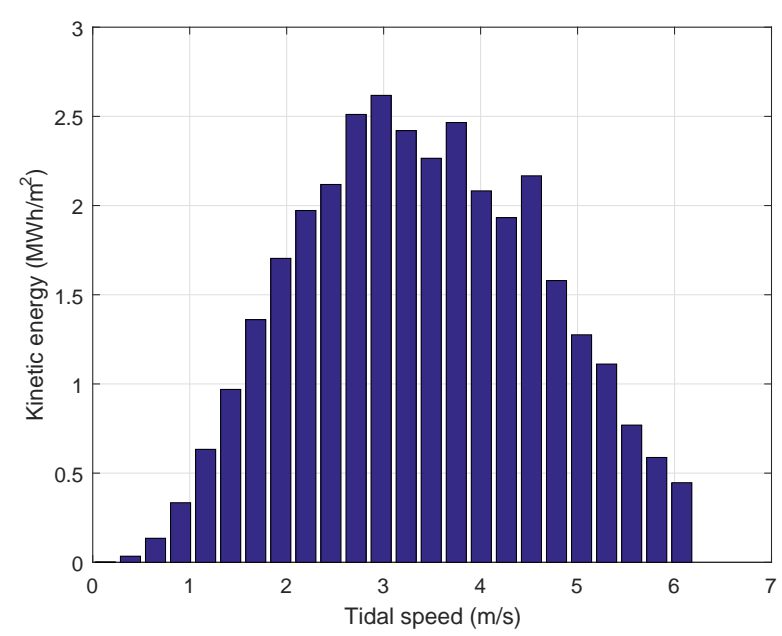

Figure 7. Tidal current energy distribution.

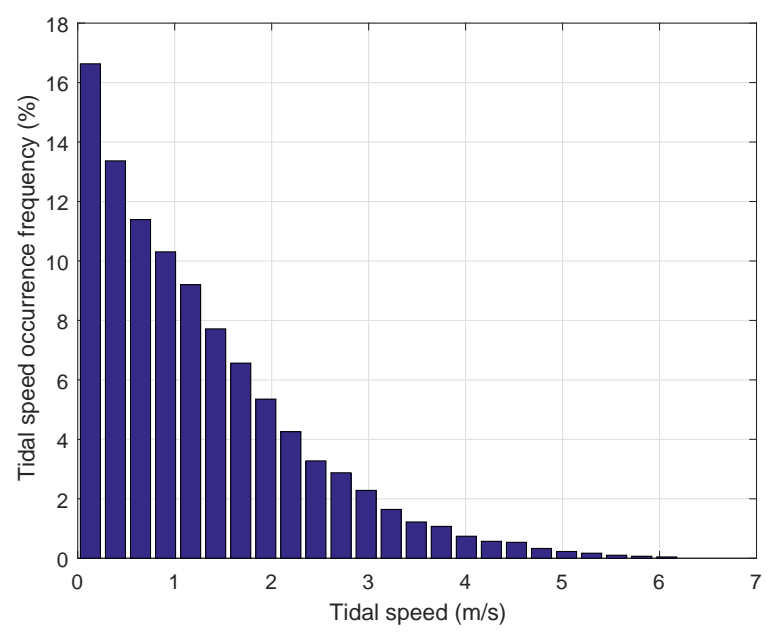

Figure 8. Tidal current amplitude speed distribution.

\subsubsection{Power Rating Choice}

To harness all the energy, a maximal power should be chosen as a rated one and an oversized system will be required. In wind turbines, mechanical limitation of power using blade or yaw pitch subsystems are adopted. However, due to the harsh submarine conditions such mechanical subsystems should be avoided. An alternative using an over-speed power limitation is adopted in this study. In this context, when the input power is less than the rated one, the power coefficient is maintained at his maximum $\left(C_{p \max }=0.455\right)$ (Table 1$)$. However, when the input power is higher than the rated one, the generator accelerates and reduces the power coefficient. This methodology is detailed in [8]. The power rating (limitation power) is chosen around $30 \%$ of the maximum power where $90 \%$ of the total energy can be harnessed (Figure 9). As the swept area considered is $1 \mathrm{~m}^{2}$, the same power ratio of $30 \%$ is maintained, and for each power rating ( $500 \mathrm{~kW}, 1.5 \mathrm{MW}, 5 \mathrm{MW}$ ) only the blade's diameter (swept area) is calculated. 


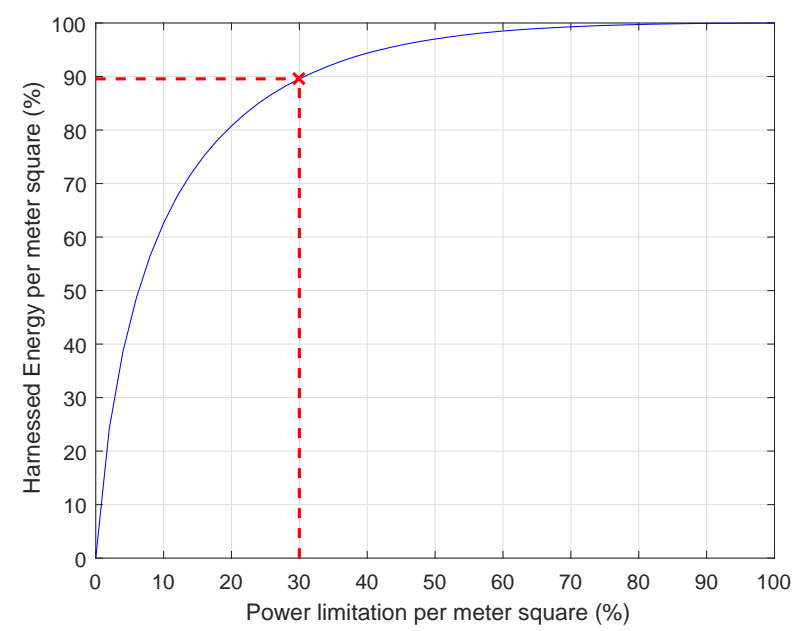

Figure 9. Harnessed energy rate versus power limitation rate.

\subsection{Gearbox Modeling}

The gearbox converts the turbine rotor slow rotational speed and high shaft torque to high rotational speed and low torque. The more its gear ratio is high, the more its cost and weight increases. However, the opposite happens to the generator because its input shaft torque decreases. It exists two main types of gear trains: parallel shaft and planetary. In this study, a planetary single stage gearbox is considered due to its high power density (Figure 10). The volume of each part of the planetary gearbox is estimated to calculate its total mass [23,24].

$$
\sum F W d^{2}=F W d_{s}^{2}+F W d_{p}^{2}+K_{r} F W d_{r}^{2}
$$

where FW is the face width of the gear, $d_{s}, d_{p}$, and $d_{r}$ are the diameter of the sun, the planets, and the ring gear respectively. $F W d^{2}$ presents the gear volume and $K_{r}=0.4$ is a scaling factor and it is selected from $[23,24]$.

The weight of the planetary single stage gearbox is a function of the gear ratio and the transmitted shaft torque [25]. Equation (4) is developed to obtain the planetary gearbox total weight.

$$
G_{\text {gear }}=\frac{W_{c}}{36050} \frac{2\left(10^{3}\right) T_{m} K_{a g}}{K_{f}}\left[\frac{1}{Z}+\frac{1}{Z r_{s n}}+r_{s n}+r_{s n}^{2}+K_{r} \frac{\left(1+\left(r_{s n}\right)^{-1}\right)}{Z}\left(r_{\text {ratio }}-1\right)^{2}\right]
$$

In the last Equation (4), $T_{m}$ is the gearbox output shaft torque and $K_{a g}$ is the application factor. It is chosen from [23] among different application factors. In fact, a factor of 1.0 is chosen when we have a perfectly smooth turbine driving a perfectly smooth generator always at a constant speed (no frictions and no vibrations). Because of the high torque fluctuations due to the high marine energy density [26], an application factor of 1.5 is chosen. $K_{f}$ is an index of tooth loads intensity and it is empirically estimated from [23]. $W_{c}$, which is the weight constant, is also estimated from [23]. $r_{\text {ratio }}$ is the single stage gearbox ratio (between the carrier and the sun gear), $r_{s n}=\left(r_{\text {ratio }} / 2\right)-1$ is the ratio between the sun and planet gears, and $\mathrm{Z}$ is the number of planet gears (Table 1).

The estimated cost of the single stage gearbox is given as

$$
C_{\text {gear }}=c_{\text {gear }} G_{\text {gear }}
$$

where $c_{\text {gear }}$ is the specific cost of the single stage gearbox (Table 1).

Concerning losses, only speed dependent ones are considered (seal losses and lubricant losses). Regarding power-dependent losses, they are negligible compared to speed dependent ones [27]. 


$$
p_{\text {gear }}=k_{g} P_{N} \frac{n_{r}}{n_{r_{N}}}
$$

In the precedent Equation (6), $k_{g}$ is the speed-dependent losses constant, $P_{N}$ is the rated power of the TST, $n_{r}$ is the rotor speed, and $n_{r_{N}}$ is the rated rotor speed.

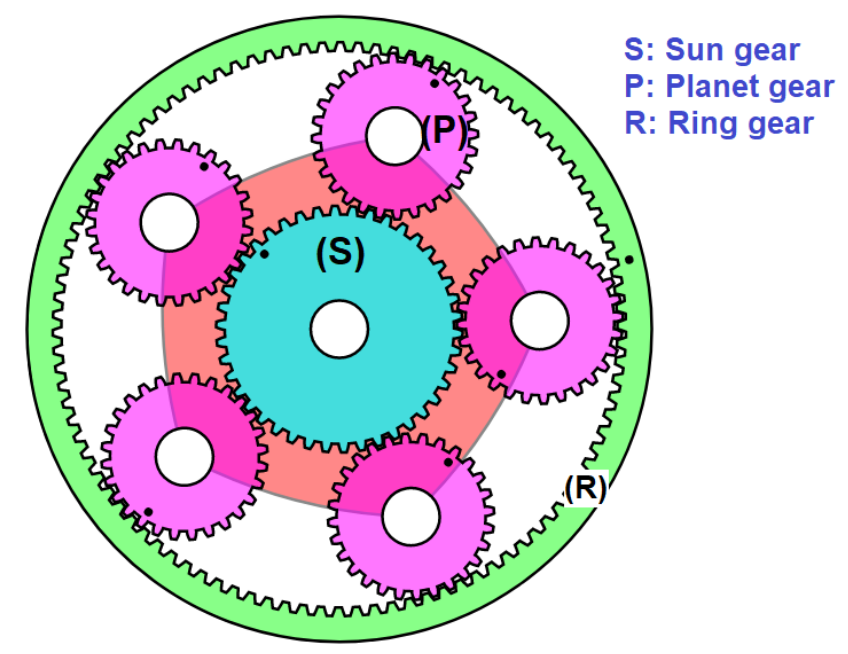

Figure 10. Illustration of a planetary gearbox with five planet gears.

\subsection{Single Stage Geared PMG Design}

The generator considered in this paper is a three phase radial flux permanent magnet one [8]. Figure 11 shows the geometric parameters of one pair of poles and its structure. The magnets are surface mounted and the generator curvature is assumed insignificant. For design purposes, the adopted modeling is a 2D analytical electromagnetic model based on magnetic circuit calculation $[18,28]$. The objective is to calculate the size of the generator knowing its specifications.

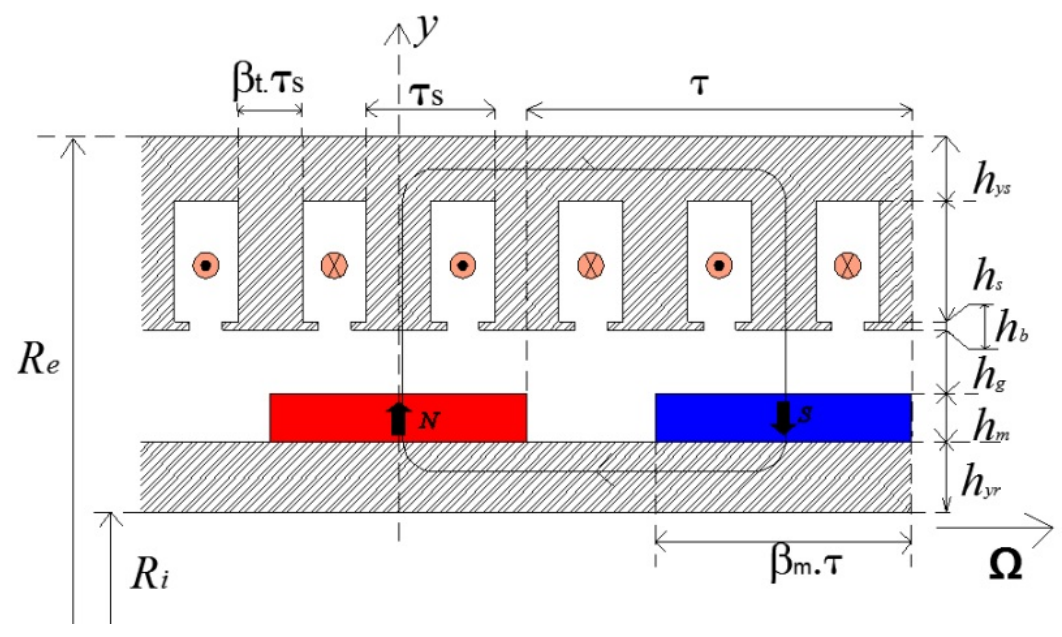

Figure 11. Basic dimensions of one pair of poles [8].

\subsubsection{Electromagnetic Torque}

The average electromagnetic torque results from the interaction between the fundamental electromotive forces and the currents of the phases (considered sinusoidal) at the nominal operating point [29].

$$
<T_{E M}>=4 \sqrt{2} A_{L} k_{b 1} B_{g_{\max }} R_{s}^{2} L_{m} \xi_{3 D} \sin \left(\beta_{m} \frac{\pi}{2}\right)|\cos (\psi)|,
$$


where $A_{L}$ is the current loading in the stator, $B_{g_{\max }}$ is the maximum air-gap flux density under the magnet, $k_{b 1}$ is the first harmonic winding factor, $\psi$ is the phase shift between the fundamental of the electromotive force and the current, $R_{S}$ is the stator radius, $L_{m}$ is the equivalent core length, and $\xi_{3 D}$ is a corrective coefficient which takes into consideration the $3 \mathrm{D}$ flow leakage.

\subsubsection{Air-Gap}

The mechanical air-gap is given by the following empirical formula [30]

$$
h_{g}=2 k_{D} R_{s}
$$

where $k_{D}$ is a coefficient, which considers the deformations caused by the forces acting on the rotating rotor.

The additional Carter air-gap $h_{g^{\prime}}$ is calculated as [30]

$$
h_{g^{\prime}}=\left(k_{c}-1\right)\left(h_{g}+\frac{h_{m}}{\mu_{r m}}\right),
$$

where $k_{c}$ is the Carter factor, $h_{m}$ is the magnet height, and $\mu_{r m}$ is the magnets relative permeability.

\subsubsection{Magnet Height}

The magnet height model calculation considers inter-polar 2D leakage flow [28]

$$
h_{m}=\frac{\tau}{2 \pi}\left[\ln \left(\frac{\left(\mu_{r m}+1\right) B_{g_{\max }} \exp \frac{-\pi}{\tau}\left(h_{g}+h_{g^{\prime}}\right)-\frac{\left(\mu_{r m}-1\right)}{\left(\mu_{r m}+1\right)} \exp \frac{\pi}{\tau}\left(h_{g}+h_{g^{\prime}}\right)-2 B_{r}}{\left(\mu_{r m}+1\right) B_{g_{\max }} \exp \frac{\pi}{\tau}\left(h_{g}+h_{g^{\prime}}\right)-\frac{\left(\mu_{r m}-1\right)}{\left(\mu_{r m}+1\right)} \exp \frac{-\pi}{\tau}\left(h_{g}+h_{g^{\prime}}\right)-2 B_{r}}\right)\right],
$$

where $B_{r}$ is the magnet's remanent flux density and $B_{g_{\max }}$ is the maximum air-gap flow density, and $\tau$ is the pole pitch.

\subsubsection{Slot Height}

The slot height depends on the current loading $A_{L}$, the fill factor $k_{f}$, and the teeth pitch ratio $\beta_{t}$.

$$
h_{s}=\frac{A_{L}}{k_{f} J\left(1-\beta_{t}\right)}
$$

\subsubsection{Stator and Rotor Yoke Height}

The stator yoke height $h_{y s}$ is determined in a way to avoid its saturation. With the same principle, the rotor yoke height $h_{y r}$ is developed [28].

$$
\begin{gathered}
h_{y s}=\beta_{m} \frac{\pi R_{s}}{2 p} \frac{B_{g_{\max }}}{B_{\text {sat }}}+\frac{1}{3} \frac{\mu_{0} \mu_{r m} \sqrt{2} A_{L} \pi^{2} R_{s}^{2}}{\left(h_{m}+\mu_{r m}\left(h_{g}+h_{g^{\prime}}\right)\right) S_{p p} m p^{2} B_{s a t}}, \\
h_{y r} \approx h_{y s}
\end{gathered}
$$

where $S_{p p}$ is the number of slots per pole per phase, $m$ is the phases number, and $p$ is pole pairs number.

\subsubsection{Teeth Pitch Ratio}

The teeth pitch ratio $\beta_{t}$ is calculated in a way to assure a non saturation of the generator when it is over-fluxed $(\psi=\pi / 2)$ and the air-gap flow density is at its maximum $B g=B g_{\max }$ along the pole [28].

$$
\beta_{t}=\frac{B_{g_{\max }}}{B_{s a t}}+\frac{\mu_{0} \mu_{r m} \sqrt{2} A_{L} \pi R_{s}}{\left(h_{m}+\mu_{r m}\left(h_{g}+h_{g^{\prime}}\right)\right) S_{p p} m p B_{s a t}}
$$




\subsubsection{Maximum Magnetic Field}

To avoid the irreversible permanent magnet demagnetization, the maximum magnetic field $H_{\max }$ has to be less than the PM coercive magnetic field $H_{c j}$. The maximum magnetic field is calculated in the worst scenario where stator flow density is opposite to the rotor flow density. $H_{\max }$ will be introduced as a constraint in the optimization process [28].

$$
\left|H_{\text {max }}\right|=\frac{\sqrt{2} A_{L} \pi R_{s}}{\left(h_{m}+\mu_{r m}\left(h_{g}+h_{g^{\prime}}\right)\right) S_{p p} m p}+\frac{\left(h_{g}+h_{g^{\prime}}\right) B_{g_{\max }}}{\mu_{0} h_{m}}
$$

\subsubsection{Iron Losses}

The specific iron losses are estimated by using the Steinmetz formula [31,32]

$$
p_{F e}=2 p_{F e 0 h}\left(\frac{f_{e}}{f_{0}}\right)\left(\frac{\widehat{B}_{F e}}{\widehat{B}_{0}}\right)^{2}+2 p_{F e 0 e}\left(\frac{f_{e}}{f_{0}}\right)^{2}\left(\frac{\widehat{B}_{F e}}{\widehat{B}_{0}}\right)^{2},
$$

where $f_{e}$ is the field frequency in the iron, $p_{F e 0 h}$ represents the specific hysteresis loss, $p_{F e 0 e}$ represents the specific eddy current loss in the laminated stator core for a frequency $f_{0}$ of $50 \mathrm{~Hz}$ and a flux density $\widehat{B_{0}}$ of $1.5 \mathrm{~T}$.

\subsubsection{Synchronous Inductance}

The synchronous inductance $L_{S}$ is the sum of the magnetizing inductance $L_{s m}$ and the leakage inductance $L_{s l}$. It is calculated as [30]

$$
L_{s m}=\frac{6 \mu_{0} L_{e} R_{s}\left(k_{w} N_{s}\right)^{2}}{\pi p^{2}\left(h_{g}+h_{g^{\prime}}\right)},
$$

where $\mu_{0}$ is the vacuum permeability constant and $N_{s}$ is the number of turns of the phase winding.

Only slot leakage and the end-winding leakage inductances are considered to calculate the leakage inductance $L_{s l}$. Skew leakage inductance is ignored because the stator slots are not skewed.

\subsection{Power Electronic Converter Design}

A two level back-to-back pulse width modulation (PWM) full scale converter is used to inject power from the generator to the grid. Its specific cost estimate is presented in Table 1. Concerning losses rate, they are considered to be about 3\% at the rated load [33].

Table 1. Modeling parameters of the tidal stream turbine system.

\begin{tabular}{lccc}
\hline \multicolumn{3}{c}{ Tidal Stream Turbine } \\
& 0.5 & 1.5 & 5 \\
Rated power $P_{N}[\mathrm{MW}]$ & 80.3 & 47.0 & 25.8 \\
Rated rotor speed $n_{r_{N}}[\mathrm{rpm}]$ & 6 & 10.3 & 18.8 \\
Rotor diameter D $[\mathrm{m}]$ & 1.0 & \\
Cut it tidal current speed $v_{i}[\mathrm{~m} / \mathrm{s}]$ & 6.2 & \\
Cut out tidal current speed $v_{\text {out }}[\mathrm{m} / \mathrm{s}]$ & 0.455 \\
Maximum power coefficient $C_{\text {pmax }}$ & \multicolumn{3}{c}{5.90} \\
Optimum tip speed ratio $\lambda_{\text {opt }}$ & 995.6 \\
Sea water density $\left[\mathrm{kg} / \mathrm{m}^{3}\right]$ & \multicolumn{3}{c}{} \\
\hline
\end{tabular}


Table 1. Cont.

\begin{tabular}{lc}
\hline \multicolumn{2}{c}{ Single Stage Planetary Gearbox } \\
\hline Gearbox application factor $K_{a g}$ & 1.5 \\
K-factor $K_{f}\left[\mathrm{~N} / \mathrm{mm}^{2}\right]$ & 2.76 \\
Gearbox weight constant $W_{c}$ & 0.6 \\
Planet gears number Z & 6 \\
Gearbox specific cost $c_{\text {gear }}[€ / \mathrm{kg}]$ & 6 \\
Speed dependent losses constant $k_{g}[\%]$ & 1.5 \\
\hline \multicolumn{1}{c}{ PMG System } & 2 \\
\hline Hysteresis losses at $1.5 \mathrm{~T}$ and $50 \mathrm{~Hz} p_{F e 0 h}[\mathrm{~W} / \mathrm{kg}]$ & 0.5 \\
Eddy-current losses at $1.5 \mathrm{~T}$ and $50 \mathrm{~Hz} p_{F e 0 e}[\mathrm{~W} / \mathrm{kg}]$ & 449.77 \\
Specific cost of electrical steel $c_{F e}[€ / \mathrm{mT}]$ & 4259.18 \\
Specific cost of copper $c_{C u}[€ / \mathrm{mT}]$ & $84,538.60$ \\
Specific cost of NdFeB magnet $c_{m}[€ / \mathrm{mT}]$ & 40 \\
Specific cost of power electronics $c_{c o n v}[€ / \mathrm{kW}]$ & \\
\hline
\end{tabular}

\section{Design Optimization}

The design optimization is based on the modeling of each part of the system (the turbine, the gearbox, the power electronics converters, and the PMG generator). The electromagnetic specifications are all the fixed design parameters, the gearbox ratio is chosen before the optimization process starting, and tidal power specifications are calculated from tidal current speed data. The analytical model can be represented by a non-linear function, which has as input a geometrical design variables vector. To evaluate the cost-function, an iterative inversion of the non-linear model is adopted. By considering the constraint, the interior-point optimization technique is used to minimize the cost-function. The optimal design is the one which has the lowest cost (Figure 12).

\subsection{Cost-Function}

The TST cost depends on its active materials weight, its structure cost, and its manufacturing cost. In this study, only the generator's active materials cost is considered in addition to the gearbox and the power electronic converter costs. The active material cost depends on the size of each material. Hence, the generator cost is calculated only from the size parameters $G=\left(L_{m}, h s, h m, h y s, \beta_{t}\right)$.

$$
\begin{gathered}
C_{g}=c_{C u} G_{C u}+c_{F e} G_{F e}+c_{m} G_{m} \\
C_{T S T}=C_{g}+C_{\text {gear }}+C_{\text {conv }},
\end{gathered}
$$

where $C_{\text {gear }}$ is the single stage gearbox cost, $C_{\text {conv }}$ is the estimated power electronics cost, $c_{\mathrm{Cu}}, c_{\mathrm{Fe}}, c_{m}$ are the copper, the iron, and the permanent magnet specific costs, and $G_{C u}, G_{F e}, G_{m}$ are the copper, the iron, and the permanent magnet weights, respectively.

The cost-function depends on the gearbox ratio and the size parameters of the PMG. However, if the analytical modeling is considered, the PMG cost will depend only on the following variables $X=\left(A_{L}, J, B_{g_{\max }}, p, R_{s}\right)$.

$$
X^{*}=\min _{X \in \mathbb{D}}\left\|C_{g}(X)\right\|,
$$

where $\mathrm{X}$ is the vector including the independent variables $\left(A_{L}, J, B_{g_{\max }}, p, R_{S}\right)$ and $\mathbb{D}$ is the set of possible solutions.

\subsection{Optimization Constraints}

The optimization is performed under electromagnetic and mechanical constraints, which define the $\mathbb{D}$ set. 
The first constraint on the pole pair number is related to the maximum electrical frequency. In fact, a high pole pair number leads to a higher electrical frequency resulting in high iron losses. To avoid this, the maximum electrical frequency $\left(f_{\max }\right)$ allowed in laminated steel core is limited, which can be considered as a limitation of the pole pair number. The second constraint is related to the ratio of slot depth to slot width. This ratio must be in the range of 4-10 to avoid excessive mechanical vibrations [12,34]. This limitation is converted to two additional constraints on the pole pair number.

The maximum magnetic field $H_{\max }(X)$ (see Equation (15)) is limited to be smaller than the permanent magnet coercive field to prevent demagnetization. The current density $J$ and the loading current $A$ are limited in the range of 3-6 A/ $\mathrm{mm}^{2}$ and 40-60 $\mathrm{kA} / \mathrm{m}$ respectively [12]. The generator efficiency is considered to be greater than 0.96 . On the other hand, the phase voltage root mean square is fixed to $690 \mathrm{~V}$.

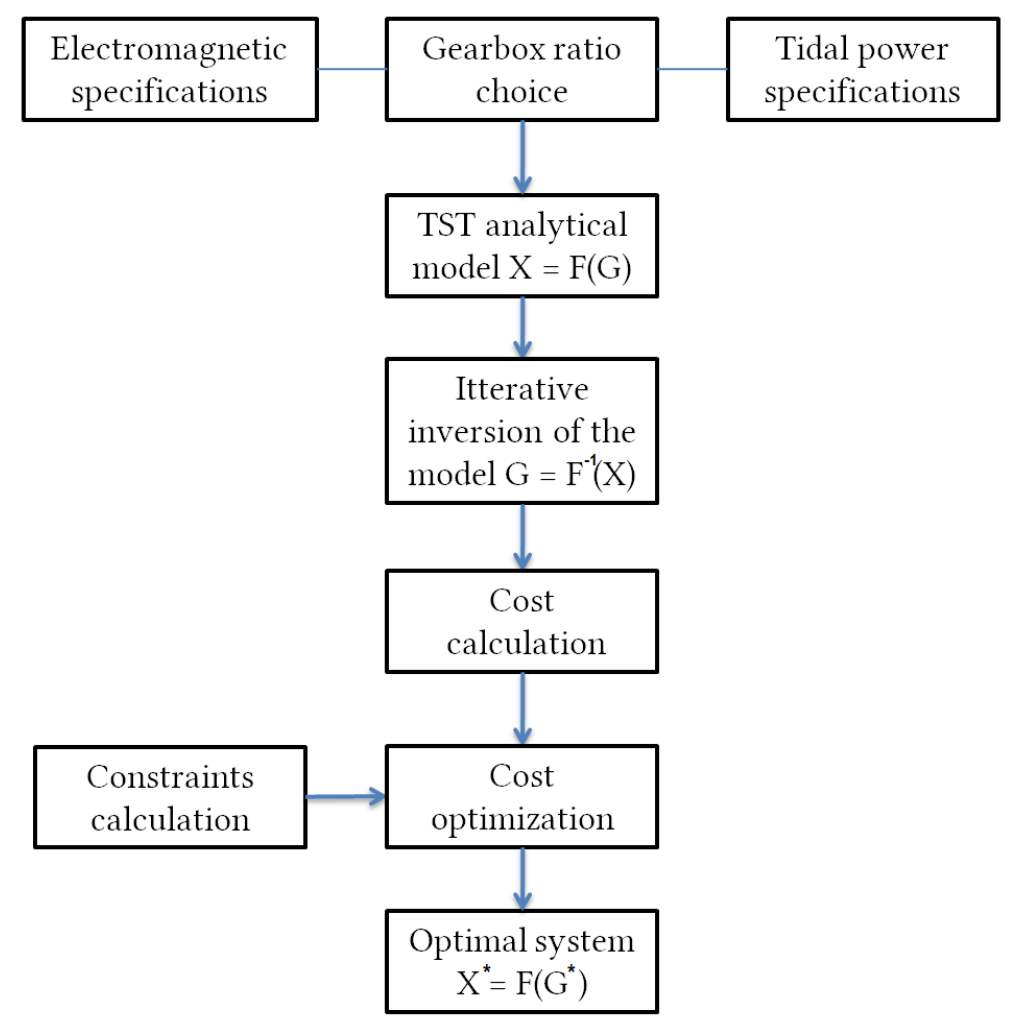

Figure 12. Flowchart describing the design optimization procedure.

\section{Design Results and Discussion}

To investigate the cost-effectiveness of the multibrid concept in TST systems, design optimization of the system is performed for different gearbox ratios $(1: 1,3: 1,5: 1,7: 1,9: 1,11: 1)$ and different power ratings ( $0.5 \mathrm{MW}, 1.5 \mathrm{MW}, 5 \mathrm{MW})$. The total harnessed energy in the Ouessant site is calculated for each power rating. According to the optimization results, the gear ratio (3:1) is the optimal one whatever the power level is (Figure 13). When it is less than (5:1), geared systems are cheaper than direct-drive ones. Concerning the estimated TST cost per kWh (Figure 14), the 1.5 MW and $5 \mathrm{MW}$ TST energy is cheaper than the $500 \mathrm{~kW}$ TST one. It seems that a rated power around 1.5 MW for the Ouessant site is more preferable than very high power ratings. 


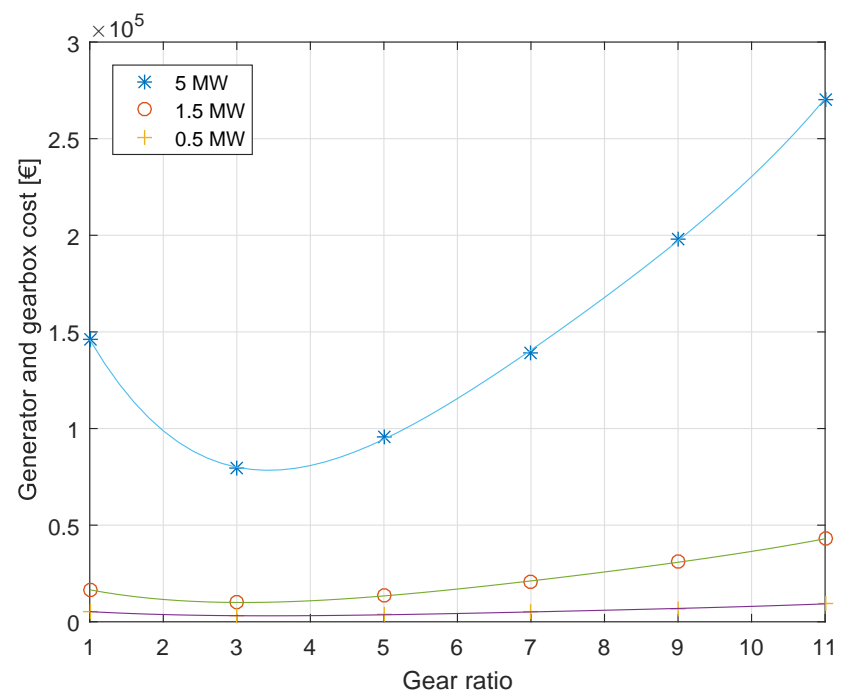

Figure 13. Tidal stream turbine (TST) estimated cost for different gear ratios and different power ratings.

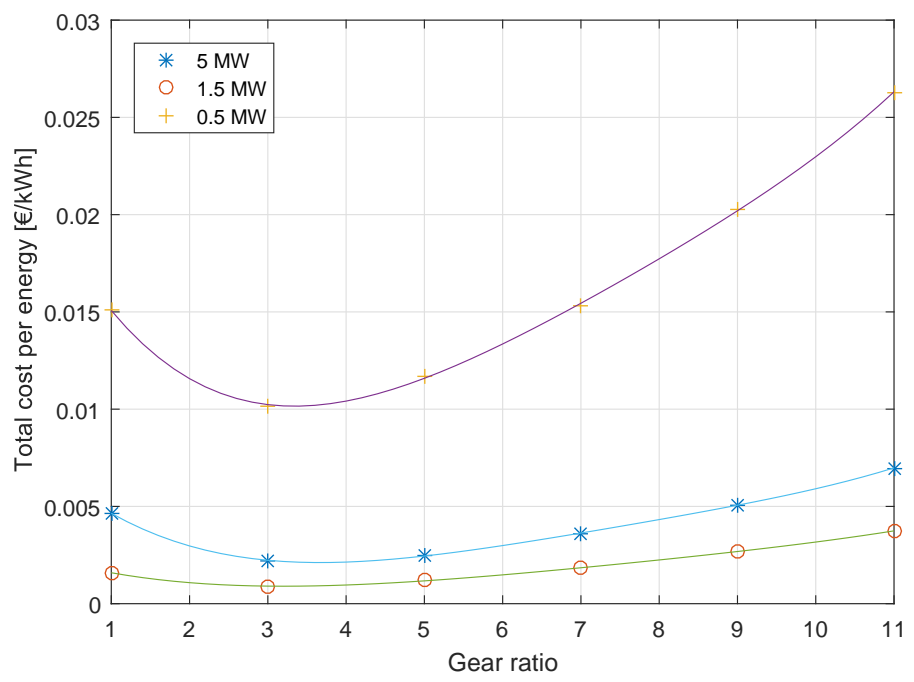

Figure 14. TST total estimated cost per kWh.

As shown in Figure 15, the generator and gearbox cost estimations are separately presented at the power of 1.5 MW. For high gear ratios the gearbox cost increases exponentially while the generator cost decreases slightly. The generator cost is however highly reduced when the gearbox ratio changes from (1:1) (direct-drive) to (3:1). The comparison shows that gearbox low ratios are more interesting especially when the power rating is high but for higher gear ratios the direct-drive configuration is preferable.

The second part considers the 1.5 MW generator's active materials cost and weight. Figure 16 shows that the direct-drive system is the heaviest one compared to the other configurations. On the other hand, the weight of the $(3: 1)$ geared generator is around $35 \%$ of the total weight of the direct-drive generator.

Regarding PMG active materials cost (Figure 17), the direct-drive configuration is the most expensive and permanent magnet's cost is extremely high compared to the other material's costs. However, the multibrid generator's active materials costs are more balanced especially when the gear ratio is high. In Figure 18 the direct-drive configuration cost is taken as a reference to be compared to 
the other configurations cost. As it is shown, the generator's active materials cost is reduced by around $65 \%$ when adopting a (3:1) gearbox. For higher gear ratios, cost reduction can reach approximately $85 \%$.

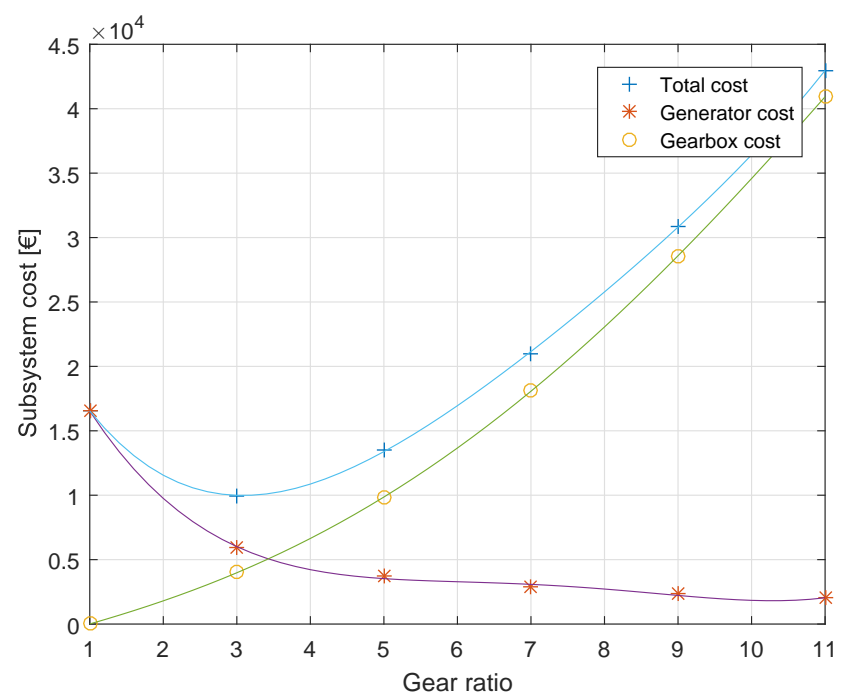

Figure 15. Gearbox and generator costs for different gear ratios at the power rating of 1.5 MW.

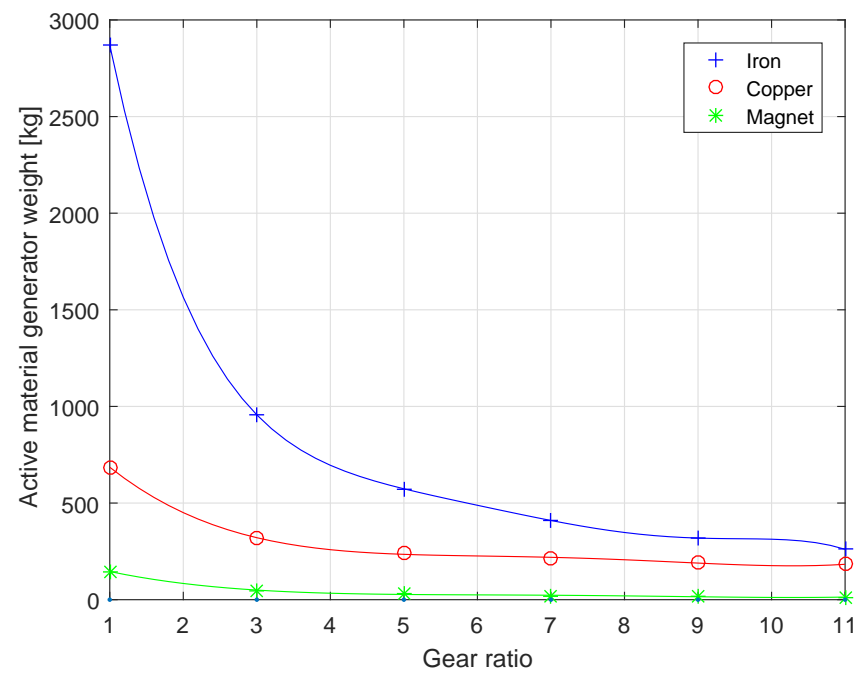

Figure 16. Generator active materials weight for different gear ratios at the power rating of $1.5 \mathrm{MW}$. 


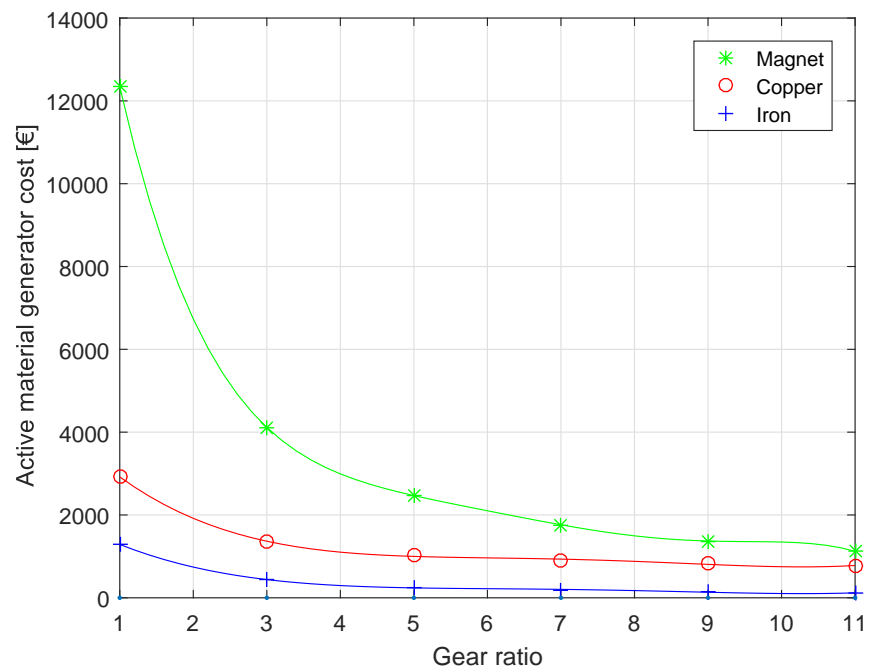

Figure 17. Generator active materials cost for different gear ratios at the power rating of $1.5 \mathrm{MW}$.

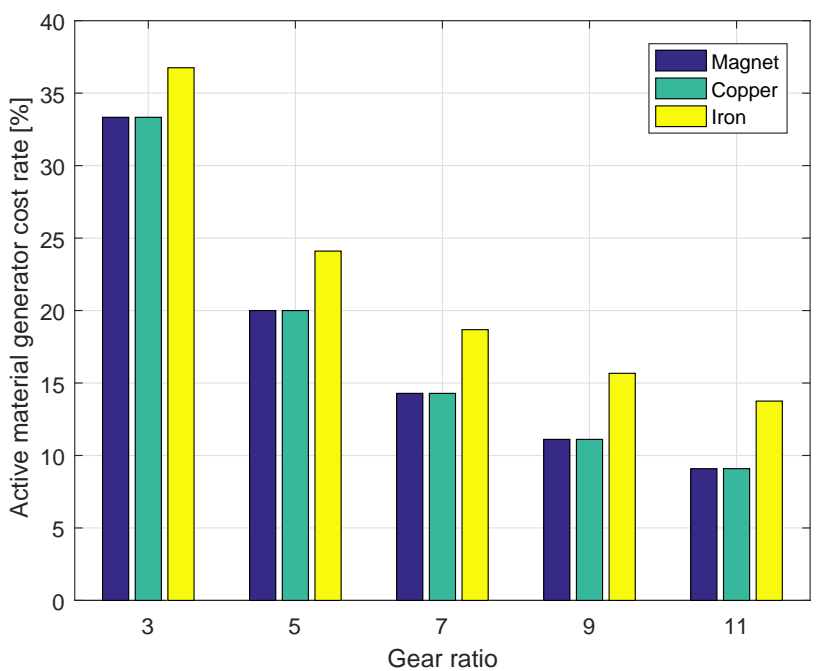

Figure 18. Active material geared generator cost compared to direct drive (DD) generator.

Figure 19 presents four poles of the designed (3:1) geared generator and Figure 20 shows a front and lateral view of the same designed generator at the rating power of $1.5 \mathrm{MW}$. The two figures give a vision of the designed generator structure and size.

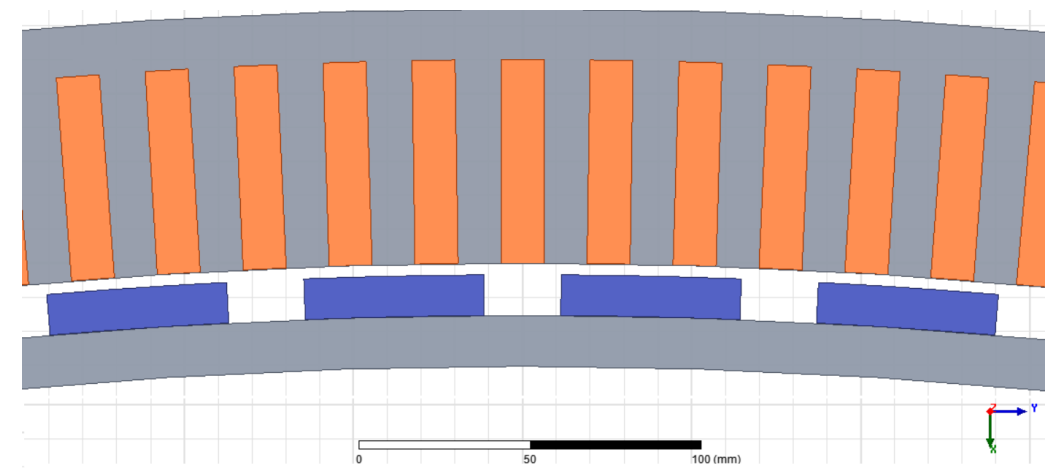

Figure 19. View of the designed (3:1) geared generator at the power rating of 1.5 MW. 


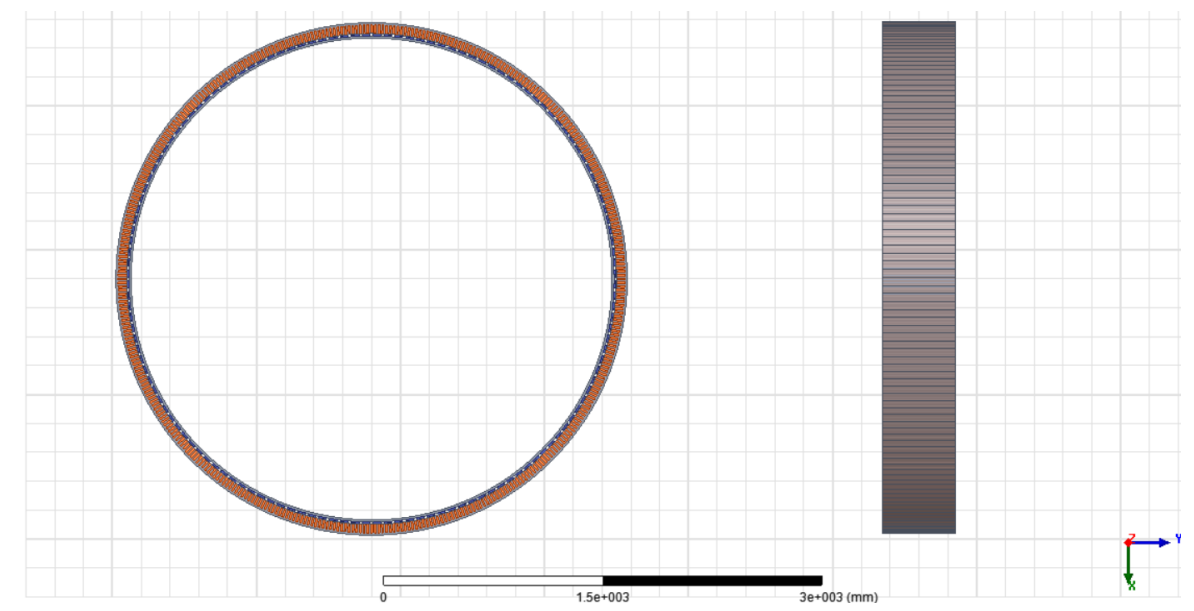

Figure 20. Front and lateral view of the designed (3:1) geared generator at the power rating of $1.5 \mathrm{MW}$.

From the above-presented results, it is shown that the Multibrid TSTs can be a promising alternative to direct-drive TSTs in terms of weight and cost. According to the Ouessant site energy potential, TSTs power ratings of around 1.5 MW are interesting especially if we consider the limited deepness of the site that limits the turbine diameter. A power rating of $5 \mathrm{MW}$ requires a turbine diameter of $18.8 \mathrm{~m}$, which is interesting if the site allows such a size.

For more accurate estimated cost, the generator structure and manufacturing costs should be considered. Moreover, the TST foundations are not addressed in this study and the gearbox is not deeply designed, which could affect the optimization results. However, these comparative study results could be useful for TST designers and could give them insight on the relevance of the multibrid concept.

\section{Conclusions}

This paper investigated the application of the multibrid concept for tidal stream turbines. In this context, a design optimization of multibrid permanent magnet generator has been proposed and the system cost-effectiveness has been analyzed by considering the Ouessant site potential energy. A planetary gearbox rough design is proposed for TST systems and the gearbox weight and cost estimations are presented. Furthermore, the study considers a $2 D$ analytical electromagnetic modeling to size the permanent magnet generator. The achieved optimization results clearly showed that multibrid tidal stream turbines are the solution of choice, in terms of weight and cost, when compared to the direct-drive topology. Otherwise, among multibrid systems, lower gear ratios seem preferable, especially for high power ratings. The cost of the 1.5 MW TST is the lowest regarding its harnessed energy in the Ouessent site and it is not far from the $5 \mathrm{MW}$ one. However, a 1.5 MW TST is preferable if the environment constraints are considered where the site deepness is limited.

Author Contributions: Conceptualization, K.T. and M.B.; Methodology, K.T. and M.B.; Software, K.T.; Validation, K.T., M.B., and Z.C.; Formal Analysis, K.T. and M.B.; Investigation, K.T.; Writing-Original Draft Preparation, K.T.; Writing-Review \& Editing, K.T., M.B., and Z.C.; Supervision, M.B. All authors have read and agreed to the published version of the manuscript.

Funding: This research received no external funding

Conflicts of Interest: The authors declare no conflict of interest. 


\section{Abbreviations}

The following abbreviations are used in this manuscript:

TST Tidal stream turbine

DD Direct drive

2D Two-dimensional

PMG Permanent magnet generator

3D Three-dimensional

AEP Annual energy production

PWM Pulse width modulation

\section{Nomenclature}

$P_{T} \quad$ Input shaft power

$A_{t} \quad$ Turbine blade swept area

$\rho \quad$ Sea water density

$C_{p} \quad$ Power coefficient

$\lambda \quad$ Tip speed ratio

$\lambda_{\text {opt }} \quad$ Optimum tip speed ratio

$\beta \quad$ Pitch angle

$v_{i} \quad$ Cut-in tidal current speed

$v_{c} \quad$ Cut-out tidal current speed

$v_{n} \quad$ Rated tidal current speed

$P_{\operatorname{Tr}} \quad$ Rated input shaft power

OCC Occurrence frequency

$F W \quad$ Gear face width

$d_{s} \quad$ Sun gear diameter

$d_{p} \quad$ Planet gear diameter

$d_{r} \quad$ Ring gear diameter

$K_{r} \quad$ Scaling factor

$T_{m} \quad$ Gearbox output shaft torque

$K_{a g} \quad$ Application factor

$K_{f} \quad$ Tooth loads intensity index

$W_{c} \quad$ Gearbox weight constant

$r_{\text {ratio }}$ Gearbox ratio

$r_{s n} \quad$ Gear ratio between sun and planet gears

Z Planet gears number

$c_{\text {gear }}$ Gearbox specific cost

$G_{\text {gear }}$ Gearbox weight

Cgear Gearbox estimated cost

$p_{\text {gear }}$ Gearbox losses

$k_{g} \quad$ Speed-dependent losses constant

$P_{N} \quad$ Tidal stream turbine rated power

$n_{r} \quad$ Rotor speed

$n_{r_{N}} \quad$ Rated rotor speed

$T_{E M} \quad$ Electromagnetic torque

$A_{L} \quad$ Stator current loading

$B_{g_{\max }} \quad$ Maximum air-gap flux density

$B_{g} \quad$ Air-gap flux density

$B_{\max } \quad$ Saturation flux density

$k_{b 1} \quad$ First harmonic winding factor

$\psi \quad$ Phase shift between the electromotive force and the current

$R_{S} \quad$ Stator radius

$L_{m} \quad$ Equivalent core length 
$\xi_{3 D} \quad 3 D$ flow leakage corrective coefficient

$k_{D} \quad$ Air-gap coefficient

$h_{g} \quad$ Mechanical air-gap

$h_{g^{\prime}} \quad$ Additional Carter air-gap

$k_{c} \quad$ Carter factor

$h_{m} \quad$ Magnet height

$\mu_{0} \quad$ Vacuum permeability constant

$\mu_{r m} \quad$ Magnets relative permeability

$B_{r} \quad$ Magnets remanent flux density

$B_{g_{\max }} \quad$ Maximum air-gap flow density

$\tau \quad$ Pole pitch

$h_{y s} \quad$ Stator yoke height

$h_{y r} \quad$ Rotor yoke height

$h_{s} \quad$ Slot height

$k_{f} \quad$ Fill factor

$\beta_{t} \quad$ Teeth pitch ratio

$p \quad$ Pole pairs number

$S_{p p} \quad$ Slots per pole per phase number

$m$ Phases number

$H_{\text {max }} \quad$ Maximum magnetic field in the magnet

$H_{c j} \quad$ Permanent magnet coercive magnetic field

$p_{F e} \quad$ Iron losses

$f_{e} \quad$ Magnetic field frequency in the iron

$p_{F e 0 h} \quad$ Specific hysteresis loss

$p_{F e 0 e} \quad$ Specific eddy current loss

$N_{S} \quad$ Phase winding number of turns

$L_{s l} \quad$ Leakage inductance

$C_{\text {conv }}$ Power electronics cost

$C_{g} \quad$ Permanent magnet generator cost

$C_{T S T}$ Tidal stream turbine cost

$c_{C u} \quad$ Copper specific costs

$c_{F e} \quad$ Iron specific costs

$c_{m} \quad$ Permanent magnet specific costs

$G_{C u} \quad$ Copper specific weight

$G_{F e} \quad$ Iron specific weight

$G_{m} \quad$ Permanent magnet specific weight

$\mathbb{D} \quad$ Set of possible solutions

$f_{\max } \quad$ Maximum electrical frequency

\section{References}

1. Benbouzid, M.; Titah-Benbouzid, H.; Zhou, Z. Ocean Energy Technologies; Abraham, M.A., Ed.; Encyclopedia of Sustainable Technologies; Elsevier: Amsterdam, The Netherlands, 2017; pp. 73-85, ISBN 978-0-128-04677-7.

2. Selin, N.E. Tidal Power. April 2019. Available online: https://www.britannica.com/science/tidal-power (accessed on 6 June 2019).

3. Flambard, J.; Amirat, Y.; Feld, G.; Benbouzid, M.; Ruiz, N. River and Estuary Current Power Overview. J. Mar. Sci. Eng. 2019, 7, 365. [CrossRef]

4. Zhou, Z.; Benbouzid, M.; Charpentier, J.F.; Scuiller, F.; Tang, T. Developments in large marine current turbine technologies-A review. Renew. Sustain. Energy Rev. 2017, 71, 852-858. [CrossRef]

5. Djebarri, S.; Charpentier, J.F.; Scuiller, F.; Benbouzid, M. Comparison of direct-drive PM generators for tidal turbines. In Proceedings of the 2014 International Power Electronics and Application Conference and Exposition, Shanghai, China, 5-8 November 2014; pp. 474-479. 
6. Zeinali, R.; Keysan, O. A Rare-Earth Free Magnetically Geared Generator for Direct-Drive Wind Turbines. Energies 2019, 12, 447. [CrossRef]

7. Keysan, O.; McDonald, A.S.; Mueller, M. A direct drive permanent magnet generator design for a tidal current turbine (SeaGen). In Proceedings of the 2011 IEEE International Electric Machines \& Drives Conference (IEMDC), Niagara Falls, ON, Canada, 15-18 May 2011; pp. 224-229.

8. Djebarri, S.; Charpentier, J.F.; Scuiller, F.; Benbouzid, M. Design methodology of permanent magnet generators for fixed-pitch tidal turbines with overspeed power limitation strategy. J. Ocean. Eng. Sci. 2019. [CrossRef]

9. Ozturk, S.; Fthenakis, V.; Faulstich, S. Failure Modes, Effects and Criticality Analysis for Wind Turbines Considering Climatic Regions and Comparing Geared and Direct Drive Wind Turbines. Energies 2018, 11, 2317.

10. Touimi, K.; Benbouzid, M.; Tavner, P. A Review-based Comparison of Drivetrain Options for Tidal Turbines. In Proceedings of the 2018 IEEE International Power Electronics and Application Conference and Exposition (PEAC), Shenzhen, China, 4-7 November 2018; pp. 1-6.

11. Touimi, K.; Benbouzid, M.; Tavner, P. Tidal stream turbines: With or without a Gearbox? Ocean. Eng. 2018, 170, 74-88. [CrossRef]

12. Li, H.; Chen, Z.; Polinder, H. Optimization of multibrid permanent-magnet wind generator systems. IEEE Trans. Energy Convers. 2009, 24, 82-92. [CrossRef]

13. Detailed Technical-Specification WWD-3. Available online: http://www.ecosource-energy.bg/uploads/ Technical_Specification_WWD3.pdf (accessed on 6 June 2019).

14. Multibrid M5000. Available online: https://en.wind-turbine-models.com/turbines/22-multibrid-m5000 (accessed on 6 June 2019).

15. Xu, Q.; Li, W.; Lin, Y.; Liu, H.; Gu, Y. Investigation of the performance of a stand-alone horizontal axis tidal current turbine based on in situ experiment. Ocean. Eng. 2016, 113, 111-120. [CrossRef]

16. Polinder, H.; Van der Pijl, F.F.; De Vilder, G.J.; Tavner, P.J. Comparison of direct-drive and geared generator concepts for wind turbines. IEEE Trans. Energy Convers. 2006, 21, 725-733. [CrossRef]

17. Hart, K.; McDonald, A.; Polinder, H.; Corr, E.J.; Carroll, J. Improved cost energy comparison of permanent magnet generators for large offshore wind turbines. In Proceedings of the European Wind Energy Association 2014 Annual Conference, Barcelona, Spain, 10-13 March 2014.

18. Djebarri, S.; Charpentier, J.F.; Scuiller, F.; Benbouzid, M. Design and performance analysis of double stator axial flux PM generator for rim driven marine current turbines. IEEE J. Ocean. Eng. 2015, 41, 50-66.

19. Titah-Benbouzid, H.; Benbouzid, M. Biofouling issue on marine renewable energy converters: A state of the art review on impacts and prevention. Int. J. Energy Convers. 2017, 5, 67-78. [CrossRef]

20. Mycek, P.; Gaurier, B.; Germain, G.; Pinon, G.; Rivoalen, E. Experimental study of the turbulence intensity effects on marine current turbines behaviour. Part I: One single turbine. Renew. Energy 2014, 66, 729-746. [CrossRef]

21. SHOM (Service Hydrographique et Ocanographique de la Marine), 3D Marine Tidal Currents in Fromveur (Ouessant island). 2014. Available online: https:/ / diffusion.shom.fr/pro (accessed on 6 June 2019).

22. El Tawil, T.; Charpentier, J.F.; Benbouzid, M. Tidal energy site characterization for marine turbine optimal installation: Case of the Ouessant Island in France. Int. J. Mar. Energy 2017, 18, 57-64. [CrossRef]

23. Radzevich, S.P. Dudley's Handbook of Practical Gear Design and Manufacture; CRC Press: Boca Raton, FL, USA, 2012.

24. Guo, Y.; Parsons, T.; King, R.; Dykes, K.; Veers, P. Analytical Formulation for Sizing and Estimating the Dimensions and Weight of Wind Turbine Hub and Drivetrain Components; Technical Report; National Renewable Energy Lab. (NREL): Golden, CO, USA, 2015.

25. Harrison, R.; Hau, E.; Snel, H. Large Wind Turbines: Design and Economics; Wiley: Chichester, UK, 2000; Volume 1.

26. Rourke, F.O.; Boyle, F.; Reynolds, A. Marine current energy devices: Current status and possible future applications in Ireland. Renew. Sustain. Energy Rev. 2010, 14, 1026-1036. [CrossRef]

27. Dubois, M.R. Review of electromechanical conversion in wind turbines. Rep. EPP00 2000, 3, 4-10.

28. Djebarri, S. Contribution à la Modelisation et à la Conception Optimale de Generatrices à Aimants Permanents Pour Hydroliennes. Ph.D. Thesis, Université de Bretagne Occidentale, Brest, France, 2015. 
29. Djebarri, S.; Charpentier, J.F.; Scuiller, F.; Benbouzid, M.; Guemard, S. Rough design of a double-stator axial flux permanent magnet generator for a rim-driven marine current turbine. In Proceedings of the 2012 IEEE International Symposium on Industrial Electronics, Hangzhou, China, 28-31 May 2012; pp. 1450-1455.

30. Pyrhonen, J.; Jokinen, T.; Hrabovcova, V. Design of Rotating Electrical Machines; John Wiley \& Sons: Chichester, UK, 2013.

31. Böhmeke, G. Development and Operational Experience of the Wind Energy Converter WWD-1. In Proceedings of the 2003 Europ Wind Energy Conference, Madrid, Spain, 16-19 June 2003.

32. Boldea, I. The Electric Generators Handbook-2 Volume Set; CRC Press: Boca Raton, FL, USA, 2005.

33. Grauers, A. Efficiency of three wind energy generator systems. IEEE Trans. Energy Convers. 1996, 11, 650-657. [CrossRef]

34. Xue, Y.S.; Han, L.; Li, H.; Xie, L.D. Optimal design and comparison of different PM synchronous generator systems for wind turbines. In Proceedings of the 2008 International Conference on Electrical Machines and Systems, Wuhan, China, 17-20 October 2008; pp. 2448-2453.

(C) 2020 by the authors. Licensee MDPI, Basel, Switzerland. This article is an open access article distributed under the terms and conditions of the Creative Commons Attribution (CC BY) license (http://creativecommons.org/licenses/by/4.0/). 